\title{
EXPERIENCE OF SEVERE ACUTE RESPIRATORY SYNDROME CORONAVIRUS-2 (SARS-COV-2) - COVID-19 AT A TERTIARY CARE HOSPITAL IN QUETTA, BALUCHISTAN
}

\author{
Naveed Asif, Shahzeb Ahmed Satti, Alveena Younas*, Mehwish Gillani*, Waqas Shaikh**, Qurat Ul Ain* \\ Combined Military Hospital Quetta/National University of Medical Sciences (NUMS) Pakistan, *Armed Forces Institute of Pathology/National University of \\ Medical Sciences (NUMS) Pakistan, ${ }^{* *}$ Combined Military Hospital Bannu/National University of Medical Sciences (NUMS) Pakistan
}

\section{ABSTRACT}

Objective: To share the experience of Severe Acute Respiratory Syndrome Coronavirus-2 (SARS-CoV-2)-COVID-19 at a tertiary care hospital in Quetta, Baluchistan.

Study Design: Cross-sectional study.

Place and Duration of Study: Department of Pathology, Combined Military Hospital Quetta, from Mar to Dec 2020.

Methodology: This study included 14,741 study participants presenting to CMH Quetta with signs and symptoms of Coronavirus Disease-19 (COVID-19) and others undergoing COVID-19 PCR for screening purpose. Nasopharyngeal swab collected from these study participants were tested for COVID-19 viral RNA by real-time Reverse Transcription Polymerase Chain reaction (RT-PCR) assay.

Results: Out of these 14,741 study participants, 1886 (12.7\%) were found to be SARS-CoV-2 PCR positive. Among 1886 study participants, $1503(80 \%)$ were males while $383(20 \%)$ were females. Mean age of the study participants was $36 \pm 14$ years. Most frequent clinical presentations were body aches $(96.5 \%)$, fever $(94.1 \%)$, cough $(66.8 \%)$ and loss of appetite (68.2\%). Around 67 $(3.5 \%)$ positive study participants were asymptomatic.

Conclusion: In this study, we observed male predominance but severity of signs and symptoms among female study participants. SARS-COVID-19 caused disease with wide range of clinical spectrum and disease can be fatal as well.

Keywords: Coronavirus disease-19, Novel coronavirus pneumonia, Nasopharyngeal swabs, Reverse transcription polymerase chain reaction.

How to Cite This Article: Asif N, Satti SA, Younas A, Gillani M, Shaikh W, Ain QU. Experience of Severe Acute Respiratory Syndrome Coronavirus-2 (SARS-COV-2) - COVID-19 At A Tertiary Care Hospital in Quetta, Baluchistan. Pak Armed Forces Med J 2021; 71(6): 2152-2156.

DOI: https://doi.org/10.51253/pafmj.v71i6.6422

This is an Open Access article distributed under the terms of the Creative Commons Attribution License (https://creativecommons.org/licenses/by-nc/4.0/), which permits unrestricted use, distribution, and reproduction in any medium, provided the original work is properly cited.

\section{INTRODUCTION}

SARS-CoV-2 also commonly known as COVID19 , first emerged as a cluster of cases of pneumonia with unknown etiology from Wuhan, Province Hubei in city of China. It was a new threat to global health. Later on, it was found out to be Novel Coronavirus as the causative agent, because of which it was initially called "Novel Coronavirus Pneumonia (NCP)" ${ }^{1}$ It is an RNA virus and has the same genus and receptor as SARS Virus. ${ }^{2,3}$ SARS-CoV which is Severe Acute Respiratory Syndrome Coronavirus and MERS-CoV (Middle East Respiratory Syndrome Coronavirus) are the previous two Coronavirus outbreaks. ${ }^{4}$ Different patterns have been observed in the disease with the virus mainly affecting the respiratory system. Diagnostic strategies range from molecular testing like RT-PCR to various serological tests. ${ }^{5}$ High Resolution Computerized Tomography (HRCT) chest has also been used as useful adjunct in the early diagnosis of the disease

Correspondence: Dr Naveed Asif, Department of Pathology, Combined Military Hospital, Quetta Pakistan

Received: 05 Mar 2021; revision received: 20 May 2021; accepted: 26 May 2021 serving as a more sensitive modality. ${ }^{6}$

Till date, there are 115, 289, 961 confirmed cases of COVID-19 globally including 2,564,560 deaths as reported by WHO. ${ }^{7}$ This third outbreak of Coronavirus has affected the population in 209 countries worldwide including Pakistan. First case of Coronavirus was reported in Pakistan Karachi, on $26^{\text {th }}$ February, 2020. ${ }^{8}$ Initially reported cases of Pakistan had travel history from Iran by road and then they travelled to Baluchistan. Some of the initial cases were first quarantined in Baluchistan at Taftan Border. Cases with travel history were the main source of infection in the initial phases of the pandemic in Pakistan. However, there has been an exponential rise by local transmission nowadays. ${ }^{9}$

Baluchistan province has been lagging behind in research studies regarding COVID-19 situation. According to SIR (Susceptible-Infected-Recovered) model, based on the spread of the virus in Baluchistan, under the assumptions mentioned in Model parameters, the estimated number of infected people was 30,00000. Twenty five percent of total population of Baluchistan was estimated to be affected with a recovery rate of $98 \% .{ }^{10}$ 
Keeping in view the lack of studies on COVID-19 in the province and also such huge number of affected individuals, this study was planned to take an insight in the current situation of COVID-19 within Baluchistan province.

\section{METHODOLOGY}

This was a cross-sectional study carried out in Department of Pathology Combined Military Hospital, Quetta from March 2020 to December 2020. Sampling technique was non-probability convenient. Study was approved from the Hospital Ethical Committee (No CMH QTA/Trg/IRB/049 dated 20 Aug 2020). A total of 14741 study participants reporting to CMH Quetta with symptoms suggestive of SARS-Cov-2 viral infection, pre-surgical screening, history of exposure to COVID-19 patients, health care professionals and travelers from endemic areas were considered for PCR testing. Informed written consent was obtained from all the participants of this study. A total of 14741 study participants were tested.

Inclusion Criteria: Patients with positive PCR results were included in the study.

Exclusion Criteria: Patients with negative results were excluded from the study.

Nasopharyngeal swabs were taken from around 2-7 days of presentation. Samples were transported to laboratory in 2-3 ml of Viral Transport Medium (VTM) at $2-8^{\circ} \mathrm{C}$ within $24-48$ hours as per hospital standard operative procedures (SOP). Qualitative detection of nucleic acid of SARS-CoV-2 in nasopharyngeal swabs was done by using Coronavirus Real-Time Reverse Transcriptase PCR kit. Extraction, amplification and detection of nucleic acid of SARS-CoV-2 were done according to manufacturer's guidelines. Extraction was carried out in biosafety cabinet Class II A 2 as per guidelines. Internal control was used in RT-PCR to ensure integrity of PCR run, identification of any PCR inhibition and to assess the purity of extraction.

After RNA extraction, $12 \mu \mathrm{l}$ of reaction mixer was prepared (by mixing: $10 \mu \mathrm{l}$ Oasig Master Mix \& $2 \mu 1$ Primer and Probe). RT-qPCR plate was prepared by loading reaction mixture $12 \mu \mathrm{l}$ per well and adding RNA sample or control $(8 \mu \mathrm{l})$. After sealing reaction plate, it was placed in thermal cycler and analyzed. Results were interpreted on basis of cycle threshold value (Ct value). A Ct- value of less than 34 was taken positive, 34-37 was considered Indeterminate while Ctvalue of more than 37 was taken as negative. Samples of study participants with indeterminate results were again analyzed after 48 hours and reported after clinical correlation. Follow-up PCR was done one week after patient became asymptomatic or about 2 weeks after initial testing.

Data analysis was done on Statistical Package for the social sciences (SPSS) version 24. Descriptive statistics mean and \pm SD and frequencies were computed. Chi Square was applied for age and co morbidities and $p$-value of $\leq 0.05$ was taken as significant.

\section{RESULTS}

A total of 14741 study participants were tested for SARS COV-2 infection from March to December 2020. Out of these 14741 study participants, 1854 (12.5\%) were COVID PCR positive, while 145 (0.9 \%) had Indeterminate results. Samples of study participants with indeterminate results were again analyzed after 48 hours and reported after clinical correlation. Out of these $145(0.9 \%)$ study participants with indeterminate results, 32 came out to be positive on repeat testing, thus making an overall positivity rate of about $12.7 \%$. Among 1886 study participants finally included in study, $1503(80 \%)$ were males while $383(20 \%)$ were females. Out of these 383 females, 11 (2.87\%) were pregnant. Mean age of the study participants was $36 \pm 14$ years. Mean age of male study participants was $36 \pm$ 13.8 years, while that of female study participants was $36.0 \pm 13.8$ years. Study participants were divided according to the age into nine main groups as shown in Table-I.

Table-I: Age group distribution of SARS COV-2 PCR positive study participants.

\begin{tabular}{l|c}
\hline Age Groups (Years) & n (\%) \\
\hline$<11$ & $44(2.3)$ \\
\hline $11-20$ & $81(4.3)$ \\
\hline $21-30$ & $541(28.7)$ \\
\hline $31-40$ & $671(35.6)$ \\
\hline $41-50$ & $279(14.8)$ \\
\hline $51-60$ & $141(7.5)$ \\
\hline $61-70$ & $102(5.4)$ \\
\hline $71-80$ & $19(1.0)$ \\
\hline$>80$ & $8(0.4)$ \\
\hline
\end{tabular}

Majority of study participants were from $31-40$ years of age. Minimum age of 2 months to maximum age of 85 years was noted. Most frequent clinical presentations were fever, body aches, cough and loss of appetite. These symptoms were more severe in female study participants. Around $67(3.5 \%)$ positive study participants were asymptomatic (Table-II). About 289 $(19.5 \%)$ males were smokers. Majority of study participants were indoor cases i.e., 1433 (76\%), while 453 (24\%) study participants were from outdoor. Out of 
453 outdoor patients, 275 (14.8\%) underwent pre surgical screening for SARS COV-2. Various comorbidities were observed in COVID positive study participants. About 104 (5.5\%) study participants were suffering from diabetes mellitus while hypertension was found in $181(9.6 \%)$ study participants. Other comorbidities included bronchial asthma in $22(1.2 \%)$ study participants, liver disease in $72(3.8 \%)$ and kidney diseases were present in $32(1.7 \%)$ study participants.

Table-II: Clinical presentations of SARS COV-2 PCR positive study participants.

\begin{tabular}{l|c}
\hline Signs \& Symptoms & n (\%) \\
\hline Fatigue/Generalized Body Aches & $1819(96.5)$ \\
\hline Fever & $1774(94.1)$ \\
\hline Loss of Appetite & $1286(68.2)$ \\
\hline Cough & $1259(66.8)$ \\
\hline Headache & $958(50.8)$ \\
\hline Loose Motions & $603(32.0)$ \\
\hline Chest Pain & $320(17.0)$ \\
\hline Decreased Sleep & $301(16.0)$ \\
\hline Myocardial Infarction & $11(0.6)$ \\
\hline $\begin{array}{l}\text { Cerebrovascular Accidents (CVA } \\
\text { including Stroke) }\end{array}$ & $9(0.5)$ \\
\hline
\end{tabular}

PCR positive study participants were classified into asymptomatic/mildly symptomatic, moderately symptomatic and severe or critical disease patients on the basis of severity of clinical symptoms, based on oxygen saturation, HRCT CO-RADS score, CRP and ferritin levels. Unfortunately, $27(1.4 \%)$ of positive study participants never reported for any treatment from hospital. Out of remaining 1859 positive study participants, $426(23 \%)$ were classified as asymptomatic/mildly symptomatic, $1247(67 \%)$ as moderately symptomatic and $186(10 \%)$ as having severe or critical disease. Asymptomatic/mildly symptomatic study participants were quarantined at home and prescribed oral Hydroxychloroquine (HCQ) initially. As the data on efficacy of various treatment modalities emerged, HCQ was stopped and Ivermectin along with azithromycin was introduced. Moderately symptomatic and critical patients were admitted to hospital in high dependency unit and Intensive Care Units (ICU) respectively. However, 276 (14.6\%) patients admitted in high dependency unit and ICU required oxygen therapy. Only $58(3 \%)$ patients admitted in ICU were placed on ventilator support. All the study participants in these two groups received methyl prednisolone or dexamethasone along with broad spectrum antibiotics and prophylactic heparin for venous thromboembolism prophylaxis. Four novel therapies were used in 72 (3.8\%) moderately symptomatic and critical patients. These included convalescent plasma in $32(44.4 \%)$ patients, tocilizumab in $24(33.3 \%)$ patients, therapeutic plasma exchange in $21(29.1 \%)$ patients and Remdesivir was used in $16(22.2 \%)$ patients. Out of these 72 patients who received novel therapy, $14(10.08 \%)$ of the patients received two novel therapies while $5(3.6 \%)$ received three novel therapies (including convalescent plasma, Tocilizumab and therapeutic plasma exchange). Remaining 53 patients received single novel therapy.

Out of 1886 positive study participants, unfortunately $38(2.0 \%)$ participants died. Among these 38 cases, 28 (73.6\%) were males while $10(26.4 \%)$ were females. Average age of participants who died was 59.1 years. In addition to advanced age and co morbidities, higher CO-RADS score (more than 50\%), raised serum ferritin (greater than $1500 \mathrm{ng} / \mathrm{ml}$ ), raised CRP (above $50 \mathrm{mg} / \mathrm{l}$ ) and higher oxygen requirement (10 L by nonrebreather oxygen mask) at the time of admission were associated with increased mortality.

Disease pattern throughout this period was assessed showing a peak of cases in month of June (477 positive cases) and then around November (355 positive cases), signifying the occurrence of a severe second wave of pandemic in second half of year 2020 (Figure). Relationship of co-morbidities with PCR positive cases was found to be significant ( $p$-value $<0.001$ ) (Table-III).

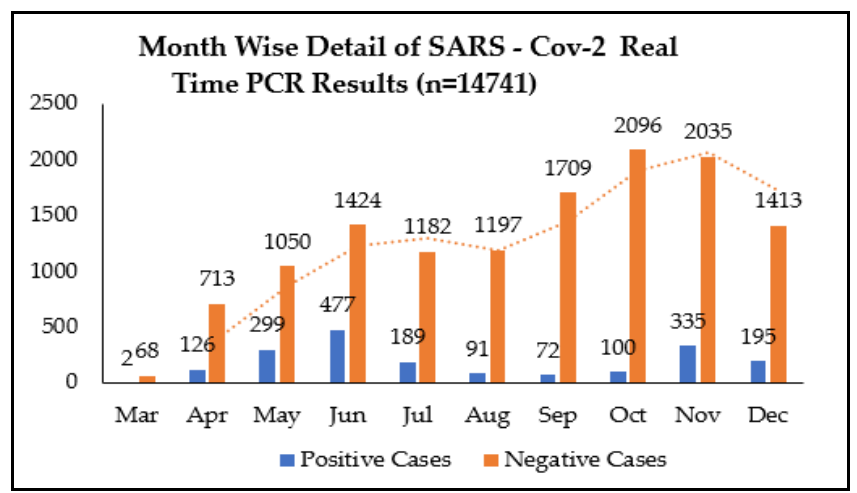

Figure: Month wise detail of SARS-Cov-2 real time PCR positive cases.

Table-III: Association of different comorbidities with COVID-19 polymerase chain reaction (PCR) positive cases.

\begin{tabular}{l|c|c|c}
\hline Comorbidities & $\begin{array}{c}\text { No of PCR } \\
\text { Positive } \\
\text { cases with } \\
\text { DM (\%) }\end{array}$ & $\begin{array}{c}\text { No of PCR } \\
\text { Positive cases } \\
\text { without DM } \\
\text { (\%) }\end{array}$ & $\begin{array}{c}p \text { - } \\
\text { value }\end{array}$ \\
\hline Diabetes Mellitus & $104(5.5 \%)$ & $1782(94.5 \%)$ & $<0.001$ \\
\hline Hypertension & $181(9.6 \%)$ & $1705(90.4 \%)$ & $<0.001$ \\
\hline Bronchial Asthma & $22(1.2 \%)$ & $1864(98.8 \%)$ & $<0.001$ \\
\hline Liver Disease & $72(3.8 \%)$ & $1814(96.2 \%)$ & $<0.001$ \\
\hline Renal Disease & $32(1.7 \%)$ & $1854(98.3 \%)$ & $<0.001$ \\
\hline
\end{tabular}




\section{DISCUSSION}

SARS COVID-19 is one of the main pathogens of human respiratory tract infection. Two extremely pathogenic viruses, SARS-COVID and MERS-COVID, have caused severe respiratory syndrome in humans, while other four human Coronaviruses (HCoV-OC43, HCoV229E, HCoV-NL63, HCoV-HKU1) have induced minor upper respiratory infection. Major SARS-COVID outbreak which involved 8422 patients had occurred during 2002-03 and involved approximately 29 countries worldwide. MERS-COVID had emerged in Middle Eastern countries in 2012 but later on spread to China. 12,13 Sequence of establishment and progression of SARS COVID-19 has been found relatively different from other six Coronaviruses but all can be classified as a single class, Betacoronavirus. SARS-COVID and MERS-COVID have ability to transmit directly to SARS COVID-19, which is an enveloped virion measuring $50-200 \mathrm{~nm}$ in diameter with a single RNA genome. Virus has 16 club-shaped glycoprotein spikes in the envelope, giving the virus a crown-like or coronal appearance and makes it able to attach with respiratory epithelium. ${ }^{14}$

Present study was conducted in a tertiary care hospital of Quetta, Baluchistan. In this study samples of 14741 study participants were included. RT-PCR for SARS-CoV-2 had been performed on these samples and our preliminary results were noteworthy for providing substantiation of SARS-CoV-2 dynamic profile in infected patients.

In our study, study participants had mean age of $36 \pm 14$ years and $1886(12.7 \%)$ were found positive on RT-PCR for SARS COVID-19. Around 1503 (80\%) study participants were male and $383(20 \%)$ were female including 20 pregnant ladies. Majority of the study participants predominantly presented with respiratory tract infections and had history of smoking. Mean age for study participants ( $36 \pm 14$ years), which we determined in our study population is quite less than populations of some studies from different regions of globe like China and other international studies.15,16 Another fact which has been revealed in our study is that out of total 1886 positive cases, $1433(76 \%)$ of study participants had been managed in indoor settings while $186(13 \%)$ study participants required ICU facility. Findings of indoor study participants were found to be comparable to studies conducted in China and US but study participants who required ICU facilities were lesser in our population as compared to popu- lations in other studies, which could be because of more young population in our study.17,18

Among the symptoms of presentation, fever and cough were the most common symptoms in study participants of our population. Similar findings were also found in other studies. ${ }^{15-17}$ Around 67 (3.5\%) positive study participants were asymptomatic in our study, which is comparable to a study conducted in Japan.

Similarly, co-morbidities like hypertension, diabetes mellitus, cardiovascular diseases, liver and kidney disease found in our study were comparable to multiple international studies. ${ }^{20,21}$ Outcome of co-morbidities were found to be associated with more lethal disease, Intensive Care Unit (ICU) admission and greater mortality. Severity of disease and mortality has been even more common in study participants with more than one comorbidity. This finding was also comparable to other international studies. ${ }^{22}$

Requirement of invasive ventilation of our study $\{58$ study participants $(4 \%)\}$ was compared with different studies and findings were comparable in some studies but lesser in other studies.23,16 Association of severity of disease, admission in ICU, ventilator support requirement and increased age had been clearly identified in our study and this association became more stronger when age of study participants was more than 55 years. Severity of symptoms with gender was also identified in our study. Another important finding of our study is that females had more severe symptoms as compared to male study participants but number of female study participants presented to us were less. Therefore, such findings cannot be generalized. These findings are consistent with other international studies. ${ }^{24,25}$

In our study $426(23 \%)$ of asymptomatic/mildly symptomatic study participants were prescribed oral Hydroxychloroquine (HCQ) initially, followed by Ivermectin along with azithromycin.

\section{CONCLUSION}

We concluded that Baluchistan province like other areas of the world is badly hit by COVID-19. In this region SARS-COVID-19 caused disease with wide range of clinical spectrum. Male gender in middle age group needs to be extra careful as this group was the maximum affected group in Baluchistan. Severity of disease, requirement of ICU care and mortality were directly linked to age of the patient and underlying comorbidities.

\section{Conflict of Interest: None.}




\section{Authors' Contribution}

NA: Direct contribution to conception, design, analysis, data interpretation, SAS: Intellectual contribution to analysis, literature review, manuscript preparation \& final approval, AY: Intellectual contribution to analysis, literature review, manuscript preparation \& final approval, MG: Manuscript preparation \& data analysis, WS: Intellectual contribution to analysis, literature review, QUA: Intellectual contribution to analysis, data interpretation \& final approval.

\section{REFERENCES}

1. Raza S, Rasheed MA, Rashid MK. Transmission potential and severity of COVID-19 in Pakistan. 2020, [Internet]. Available at: https://preprints.org/manuscript/202004.0004/v1 [Accessed on April 1, 2020]

2. Rothan HA, Byrareddy SN. Epidemiology and pathogenesis of Coronavirus disease (COVID-19) outbreak. J Autoimmun 2020; 109(5): 102433.

3. Bilgin S, Kurtkulagi O, Kahveci GB, Duman TT, Tel BM. Millennium pandemic: A review of Coronavirus disease (COVID-19). Exp Biomed Res 2020; 3(2): 117-125.

4. Zhou P, Yang XL, Wang XG, Hu B, Zhang L, Zhang W. A pneumonia outbreak associated with a new Coronavirus of probable bat origin. Nature 2020; 579(7798): 270-273.

5. Dramé M, Tabue TM, Proye E, Hequet F, Hentzien M, Kanagaratnam L. Should RT-PCR be considered a gold standard in the diagnosis of COVID-19. J Med Virol 2020; 92(11): 2312-2313.

6. Hanif N, Rubi G, Irshad N, Ameer S, Habib U, Zaidi SRH. Comparison of HRCT chest and RT-PCR in diagnosis of COVID19. J Coll Physicians Surg Pak 2021; 31(Supp-1): S1-S6.

7. World Health Organization. Coronavirus disease (COVID-19) pandemic, 2019. [Internet] Available at: https://www.who.int/ emergencies/diseases/novel-coronavirus-2019. [Accessed on Jun 20, 2020]

8. Noreen N, Dil S, Niazi SUK, Naveed I, Khan NU, Khan FK, et al. Coronavirus disease (COVID-19) pandemic and Pakistan; limitations and gaps. Glob Biosec 2020; 1(3): 11-20.

9. Waris A, Atta UK, Ali M, Asmat A, Baset A. COVID-19 outbreak: Current scenario of Pakistan. New Microbes New Infect 2020; 35(4): 100681.

10. Arif M, Kakar A, Larik E. Estimation of the final size of the COVID-19 epidemic in Balochistan, Pakistan. Int J Front Sci 2020; 4(2): 78-80.

11. Long YJ, Yang WU, Zhen QU, Ming H, Zhang Y, Zhang AN. Pathogenesis and treatment of COVID-19: A system review. Biomed Environ Sci 2021; 34(1): 50-60.
12. Chan JF, Yuan S, Kok KH, To KK, Chu H, Yang J, et al. A familial cluster of pneumonia associated with the 2019 novel coronavirus indicating person-to-person transmission: a study of a family cluster. Lancet 2020; 395(10223): 514-523.

13. Huang C, Wang Y, Li X, Ren L, Zhao J, Hu Y, et al. Clinical features of patients infected with 2019 novel coronavirus in Wuhan, China. Lancet 2020; 395(10223): 497-506.

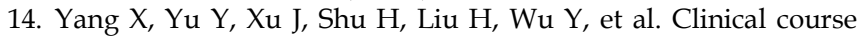
and outcomes of critically ill patients with SARSCoV-2 pneumonia in Wuhan, China: a single-centered, retrospective, observational study. Lancet Respir Med 2020; 8(5): 475-481.

15. Zhou F, Yu T, Du R, Fan G, Liu Y, Liu Z, et al. Clinical course and risk factors for mortality of adult inpatients with COVID19 in Wuhan, China: a retrospective cohort study. Lancet 2020; 395(10229): 1054-1062.

16. Boehmer TK, DeVies J, CarusoE, Santen KL, Tang S, Black CL et al. Changing age distribution of the COVID-19 pandemicUnited States, May-August 2020. Morb Mortal Wkly Rep 2020; 69(39): 1404-1409.

17. Shang Y, Pan C, Yang X, Zong M, Shang X, Wu Z, et al. Management of critically ill patients with COVID-19 in ICU: statement from front-line intensive care experts in Wuhan, China. Ann Intens Care 2020; 10(1): 73-76.

18. Murthy S, Gomersall CD, Fowler RA. Care for critically ill patients with COVID-19. J Am Med Assoc 2020; 323(15): 1499-1500.

19. Iwasaki A, Grubaugh ND. Why does Japan have so few cases of COVID-19. EMBO Mol Med 2020; 12(5): e12481.

20. Xie H, Zhao J, Lian N, Lin S, Xie Q, Zhuo H. Clinical characteristics of Non-ICU hospitalized patients with coronavirus disease 2019 and liver injury: a retrospective study. Liver Int 2020; 40(6): 1321-1326.

21. Baradaren A, Ebrahimzadeh MH, Baradaran S. Prevalence of comorbidities in COVID-19 patients: a systematic review and meta-analysis. Arch Bone Jt Surg 2020; 8(Suppl-1): 247-255.

22. Izcovich A, Ragusa MA, Tortosa F, Lavena Marzio MA, Agnoletti C, Bengolea A, et al. Prognostic factors for severity and mortality in patients infected with COVID-19: A systematic review. PLoS ONE 2020; 15(11): e0241955.

23. Botta M, Tsonas AM, Pillay J, Boers LS, Geke A, Bos LDJ. Ventilation management and clinical outcomes in invasively ventilated patients with COVID-19 (PRoVENT-COVID): a national, multicentre, observational cohort study. Lancet Respir Med 2021; 9(2): 139-148.

24. Jin JM, Bai P, He W. Gender differences in patients with COVID19: focus on severity and mortality. Front Public Health 2020; 8(2): 152.

25. Bhopal R. COVID-19 worldwide: we need precise data by age group and sex urgently. Br Med J 2020; 369(1): m1366. 